\title{
Release of Vasopressin by the Fetal Lamb during Premature Parturition Induced with Corticotropin
}

\author{
R. I. STARK, ${ }^{(28)}$ S. S. DANIEL, M. K. HUSAIN, J. MILLIEZ, H. O. MORISHIMA, L. S. JAMES, AND \\ R. VAN DE WIELE
}

The Division of Perinatal Medicine, Departments of Pediatrics, Obstetrics and Anesthesiology, College of Physicians and Surgeons, Columbia University and Babies Hospital, New York City, New York, USA

\begin{abstract}
Summary
These studies were implemented to assess the relationship between fetal vasopressin secretion and the progression of parturition as well as the contribution of specific stimuli to vasopressin release during labor. In chronically catheterized fetal lamb preparations, labor was induced by infusion of adrenocorticotropin $(12.5 \mathrm{mg} / \mathrm{kg} / \mathrm{hr})$ to seven fetuses at $130 \pm 1$ day of gestation. Before labor, fetal plasma vasopressin concentrations were $2.1 \pm$ $1.4 \mathrm{pg} / \mathrm{ml}$ and remained low $(5.3 \pm 3.4 \mathrm{pg} / \mathrm{ml})$ during prodromal and early phases of labor, but rose significantly in the active and expulsive phases $(39.6 \pm 27.5$ and $173.3 \pm 152.9 \mathrm{pg} / \mathrm{ml})$ to reach peak values at delivery $(584.2 \pm 433 \mathrm{pg} / \mathrm{ml})$ and decrease by 30 min after birth $(359.8 \pm 90.0 \mathrm{pg} / \mathrm{ml})$.

At delivery, fetal plasma vasopressin concentrations were strongly correlated $(P<0.001)$ with hormone values obtained during the latter phases of labor. Fetal arterial $\mathrm{pH}$ and oxygen tension was inversely correlated with plasma vasopressin $(P<$ 0.01). No similar correlations were found with arterial $\mathrm{PCO}_{2}, \mathrm{~K}$, $\mathrm{Na}, \mathrm{Cl}$, osmolality, or packed cell volume. Unexpectedly, we observed a significant $(P<0.001)$ and progressive decrease in fetal oxygen tension during the induction process. Other characteristics of adrenocorticotropin-induced parturition seemed to mimic those of spontaneous labor.
\end{abstract}

\section{Speculation}

Many of the biophysical and biochemical changes that occur during spontaneous term labor in the sheep can be studied in a more controlled fashion during premature labor induced by infusion of adrenocorticotropin to the fetus. Vasopressin hypersecretion during the latter stages of labor is in part mediated by hypoxia. The elevated plasma hormone concentrations may play a major role in the fetal cardiovascular response to hypoxia including the redistribution of cardiac output. The progressive gradual decrease in fetal oxygen tension noted before the onset of labor may be related to morphologic changes at the fetal maternal interface in the placenta.

Vasopressin concentrations are markedly elevated at birth in the umbilical cord plasma of human infants $(6,10,19)$. Hormone concentrations are particularly high in the newborn after vaginal delivery or cesarean section preceded by labor. The stimulus to vasopressin release has been attributed to the stress and hypoxia that may accompany delivery, but in the human there are no clear correlations (19). More specifically, Hadeed et al. (10) have suggested that cranial compression during passage through the cervical canal may be the impetus for fetal vasopressin hypersecretion, whereas others have linked vasopressin secretion with the hypothalamic mechanisms initiating or maintaining parturition (5).

The potential ramifications of enhanced vasopressin secretion in the fetus have been more extensively explored in the chronically instrumented fetal lamb model. Alexander et al. (2) reported generally undetectable values for fetal vasopressin (below the level of sensitivity of the bioassay) until the last few days of gestation; thereafter, hormone concentrations rose markedly. In contradistinction, we found an increased vasopressin secretion only after the onset of spontaneous uterine contractions (23). A number of stressful conditions including fetal hypoxia (4), hemorrhage (3), umbilical cord occlusion (9), and hyperosmolar challenge (1) are accompanied by increases in fetal plasma vasopressin. The potential for any one of these to stimulate the parturient rise in vasopressin is apparent. Iwamoto et al. (13) have speculated that a role for vasopressin in the fetus may be in its effect on the redistribution of cardiac output and as such plays an important part in the fetal cardiovascular response to stress.

The present study was designed to assess the relationship between fetal vasopressin release and the progression of parturition as well as the contribution of specific stimuli to vasopressin secretion during labor. There are practical problems in carrying out experiments of this nature during spontaneous term labor because of the difficulties in predicting the timing of the parturient process. Therefore, we elected to carry out our investigations utilizing the more consistent and predictable model of premature parturition induced by infusion of adrenocorticotropin (ACTH) to the fetus. Liggins (15) has shown that ACTH-induced labor is accompanied by many of the same hormonal changes that accompany spontaneous labor.

\section{PROCEDURES AND METHODS}

\section{SURGICAL PREPARATION}

Under spinal anesthesia, polyethylene catheters were implanted in the carotid artery and jugular vein of nine fetal lambs of 120 to 124 days of gestation. Catheters were also placed in the amniotic fluid cavity and maternal femoral artery and vein. Anesthesia, operation, and pre- and postoperative care of the mix breed ewes were essentially the same as those used and described in detail in previous studies (23). Two of the seven pregnancies were twin gestations; the umbilical artery of the second fetus was catheterized at birth in both of these experiments.

\section{EXPERIMENTAL PROCEDURES}

All studies were performed at least 7 days after surgery. The ewes were maintained in a cart with freedom to lie or stand and with ready access to food and water. Induction of labor was begun at $130 \pm 1$ day of gestation with the infusion of Synacthin (12.5 $\mathrm{mg} / \mathrm{kg} / \mathrm{hr}$ ) (Ciba Laboratories Ltd., Horsham, England) into the jugular vein of seven fetuses. The Synacthin was diluted in $0.9 \%$ normal saline solution and infused at a constant rate of $1 \mathrm{ml} / \mathrm{hr}$. Dosages were based on an estimated fetal weight of 2.5 to $2.8 \mathrm{~kg}$ and depended on the gestational age of the initiation of infusion (7). The infusion was discontinued immediately before delivery. 
Continuous measurement of amniotic fluid and fetal blood pressure commenced with the start of infusion using Statham P23BB transducers, and these were recorded on a Beckman Offner dynograph recorder.

For comparative purposes only, labor was qualitatively divided into four stages as follows: prodromal labor, irregularly timed uterine contractions evidenced by 5 to $10 \mathrm{~mm} \mathrm{Hg}$ amniotic fluid pressure; early labor, regular uterine contractions at 1 - to 3 -min intervals of 5 to $10 \mathrm{~mm} \mathrm{Hg}$; active labor, regular uterine contractions at 1- to 2-min intervals of 10 to $20 \mathrm{~mm} \mathrm{Hg}$; and expulsive labor, regular uterine contractions of greater than $20 \mathrm{~mm} \mathrm{Hg}$ with superimposed expulsive movements.

Fetal arterial blood in $3 \mathrm{ml}$ heparinized aliquoits was collected before the study, every $8 \mathrm{hr}$ during the first $48 \mathrm{hr}$ of ACTH infusion, and thereafter every $4 \mathrm{hr}$ until the onset of uterine contractions. Periodic samples were obtained during the various phases of labor, at delivery, and at $30 \mathrm{~min}$ after birth. The sample was divided and immediately placed either in chilled tubes containing $4.3 \mathrm{mg}$ of EDTA for vasopressin assay $(1.7 \mathrm{ml})$ or plain tubes for electrolytes and osmolality determination $(0.7 \mathrm{ml})$. Samples were than centrifuged at $1500 \times g$ for $20 \mathrm{~min}$ and stored at $-20^{\circ} \mathrm{C}$. The samples from each animal were batched for biochemical determinations. One-half $\mathrm{ml}$ of blood was reserved for $\mathrm{pH}$, arterial blood gases, and packed cell volume determinations.

Two fetuses were used for control experiments in which saline was infused at a rate of $1 \mathrm{ml} / \mathrm{hr}$ for $96 \mathrm{hr}$, and arterial blood samples were obtained on the same schedule as the ACTH-infused animals.

\section{BIOCHEMICAL ASSAYS}

After extraction from $0.5 \mathrm{ml}$ of plasma with acetone, vasopressin was measured by radioimmunoassay as described previously (12). Intra-assay coefficients of variation calculated for five replicate samples of four pooled sheep plasmas with vasopressin concentrations in the range of $1.5,3.0,12$, and $20 \mathrm{pg} / \mathrm{ml}$ were $8.9,10.1,12.1$, and $8.8 \%$, respectively. Interassay variation of the $50 \%$ intercept point on the standard curve of these same assays was $8.2 \%$.

Total solute concentration of plasma (osmolality) was determined by freezing point depression, chloride with chloridometer, and sodium and potassium by flame photometry (9). Blood $\mathrm{pH}$, $\mathrm{PCO}_{2}$, and $\mathrm{PO}_{2}$ were determined within 10 min of sampling using microelectrodes and a Radiometer $\mathrm{pH}$ meter and gas analyzer.

\section{STATISTICAL METHODS}

Analysis of variance techniques were used to test the changes in measured values during the progression of these studies. For individual comparisons, the Tukey procedure was used. Unless otherwise stated, mean values are given with \pm S.D. Differences between different groups of fetuses or between ewes and fetuses were tested for significance using the $t$ test for small samples. Linear regression analysis with one independent variable used a log linear plot because it appeared to better fit the data, particularly at the very high and low levels of vasopressin (25).

\section{RESULTS}

\section{CONTROL PERIOD}

During the 7-day postoperative recovery period before the initiation of the study, periodic measurements of vasopressin had a mean of $1.3 \pm 0.4 \mathrm{pg} / \mathrm{ml}$ (range less than 0.8 to $3.5 \mathrm{pg} / \mathrm{ml}$ ). On the day of the study before infusion of ACTH or saline the mean fetal arterial blood values were as follows: $\mathrm{pH}, 7.370 \pm 0.02 ; \mathrm{PCO}_{2}$, $45.5 \pm 2.6 \mathrm{~mm} \mathrm{Hg} ; \mathrm{PO}_{2}, 22.4 \pm 2.0 \mathrm{~mm} \mathrm{Hg}$; and packed cell volume (hematocrit) $35.1 \pm 3.5 \%$. Mean systolic and diastolic fetal blood pressure was $60 \pm 3.2$ and $40 \pm 4.4 \mathrm{~mm} \mathrm{Hg}$, and heart rate was $156 \pm 6.2$ beats $/ \mathrm{min}$. These values are all within the range of normal for chronically catherized animals in a steady state recorded in our laboratory.

\section{LABOR INDUCTION AND BIRTH CHARACTERISTICS}

Fetal blood pressure and heart rate were recorded throughout the period to the onset of labor, and values showed no significant fluctuations. Signs of impending labor included distention of the udder 12 to $48 \mathrm{hr}$ before delivery. Often on the day before labor the ewe refused feed, and during this period, her restless behavior and scraping at the bedding made continuous blood pressure monitoring difficult to interpret.

The interval between initiation of ACTH infusion and the onset of labor varied from 68 to $96 \mathrm{hr}$ and was greatest in the two twin pregnancies. The mean duration of uterine activity was $13.4 \pm 5.6$ hr. Rupture of amniotic membranes occurred at a mean of $3.8 \pm$ $4.1 \mathrm{hr}$ before delivery. Delivery occurred at a mean of $133.3 \pm 1.7$ days of gestation (term, 147 days). Neither the duration of uterine activity nor the duration of any phase of labor was correlated with either the plasma vasopressin concentration of the fetus at birth or the hormone concentration during that phase of labor. Duration of the interval between rupture of amniotic membranes and delivery was not significantly related to fetal plasma vasopressin concentration at birth.

The mean birth weight of the fetuses was $2.7 \pm 0.3 \mathrm{~kg}$. Six of the nine newborn lambs were in good condition at birth, requiring only maternal stimulation without other intervention, whereas one animal required more than this stimulation to initiate respiration. Two newborns had no spontaneous respirations for the first $2 \mathrm{~min}$ of life and were intubated and manually ventilated with an $\mathrm{FIO}_{2}$ of $50 \%$ until initiation of sustained spontaneous respiration. All newborns survived through the first hr of life.

\section{VASOPRESSIN CONCENTRATIONS}

Vasopressin concentrations in fetal plasma during various phases of labor are presented in Figure 1. The mean value before the institution of infusion was $1.85 \pm 0.3 \mathrm{pg} / \mathrm{ml}(N=9)$ and was similar to that found during the postoperative recovery period, 1.3 $\pm 0.3 \mathrm{pg} / \mathrm{ml}(N=25)$. In fetuses infused with ACTH, the mean vasopressin concentration was $2.0 \pm 1.4 \mathrm{pg} / \mathrm{ml}$ before labor $(N$

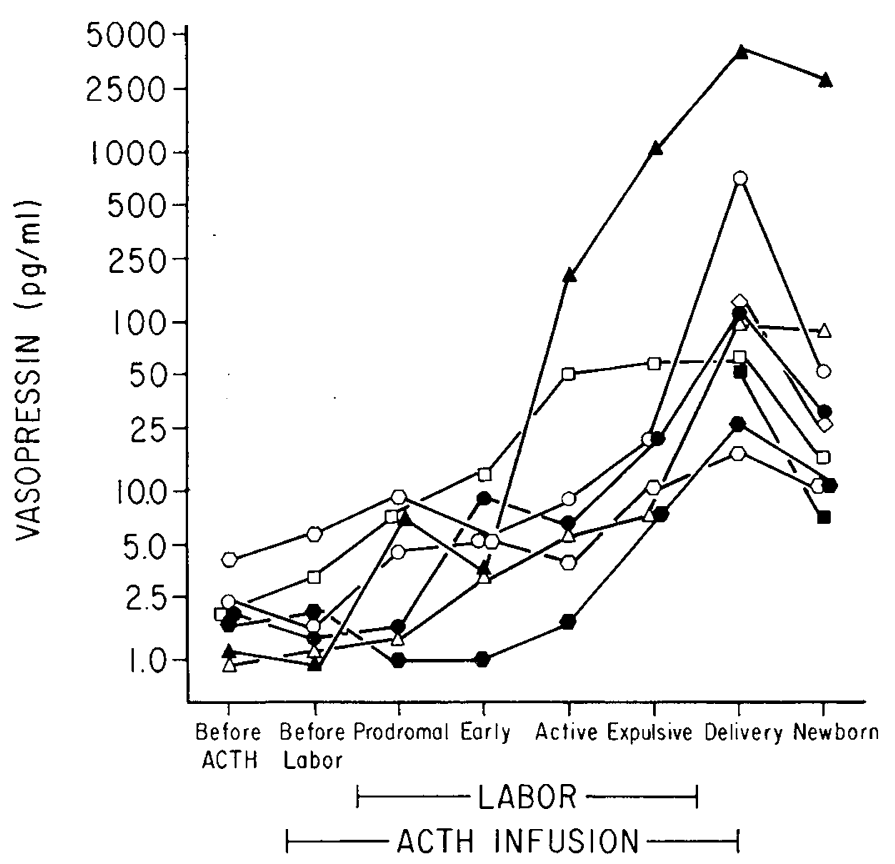

Fig. 1. Plasma vasopressin $(\mathrm{pg} / \mathrm{ml})$ in fetal and newborn lambs before, during, and after premature parturition induced by infusion of ACTH to the fetus. The values before and during labor represent the mean of from two to 10 individual vasopressin determinations. Fetus $167,($ ); fetus 835 , (๑); fetus 116, $\triangle$ ); fetus 195, (๑); fetus 396, ( $\bigcirc$ ); fetus $884,(\square)$; nonACTH-infused twin of $396(\diamond)$; fetus 884 , (苂). 
$=51)$; in prodromal and early labor, $5.3 \pm 3.4 \mathrm{pg} / \mathrm{ml}(N=25$; range, 1.0 to $30 \mathrm{pg} / \mathrm{ml})$; in active labor, $39.6 \pm 27.5 \mathrm{pg} / \mathrm{ml}(N=$ 28 ; range, 1.0 to $200 \mathrm{pg} / \mathrm{ml}$ ); and during the expulsive phase, 173.3 $\pm 152.9 \mathrm{pg} / \mathrm{ml}(N=20$; range, 5.0 to $1090 \mathrm{pg} / \mathrm{ml})$. The mean plasma hormone concentration at delivery in nine animals was $584.2 \pm 433 \mathrm{pg} / \mathrm{ml}$ (range, 15 to $4000 \mathrm{pg} / \mathrm{ml}$ ), and at $30 \mathrm{~min}$ after birth, it was $359.8 \pm 90.0 \mathrm{pg} / \mathrm{ml}$ (range, 8 to $2400 \mathrm{pg} / \mathrm{ml}$ ). Using techniques of analysis of variance with a fixed random design, the mean values of fetal vasopressin before and during the early phase of experimental induction of labor were not significantly different from those in prodromal or early labor; however, hormone concentrations increased significantly during active labor $(P<0.05)$, expulsive labor $(P<0.01)$, and at delivery $(P<0.01)$. There was a significant increment in hormone concentration between active labor and delivery $(P<0.05)$, but not between values obtained during the expulsive phase of labor and those obtained at delivery.

The fetal plasma vasopressin concentrations at delivery were strongly correlated with the hormone values obtained during the active and expulsive phases of labor with regression coefficients $r$ $=0.955$ and $0.985(P<0.001)$. A similar correlation was not obtained between hormone levels before or during prodromal and early labor with those at delivery.

The concentrations of vasopressin throughout the study in two control animals infused with normal saline were $1.4 \pm 0.4 \mathrm{pg} / \mathrm{ml}$ (range, 0.8 to $3.5 \mathrm{pg} / \mathrm{ml}$ ). There was no apparent increase in vasopressin concentration with blood sampling alone in either animal.

Maternal blood samples for vasopressin assay were obtained from five ewes. Plasma vasopressin before infusion was $1.7 \pm 0.3$ $\mathrm{pg} / \mathrm{ml}$ and remained unchanged throughout the infusion $(2.1 \pm$ $0.8 \mathrm{pg} / \mathrm{ml})$. The hormone concentration rose only during the expulsive phase of labor $(3.0 \pm 1.2 \mathrm{pg} / \mathrm{ml})$. There was no apparent
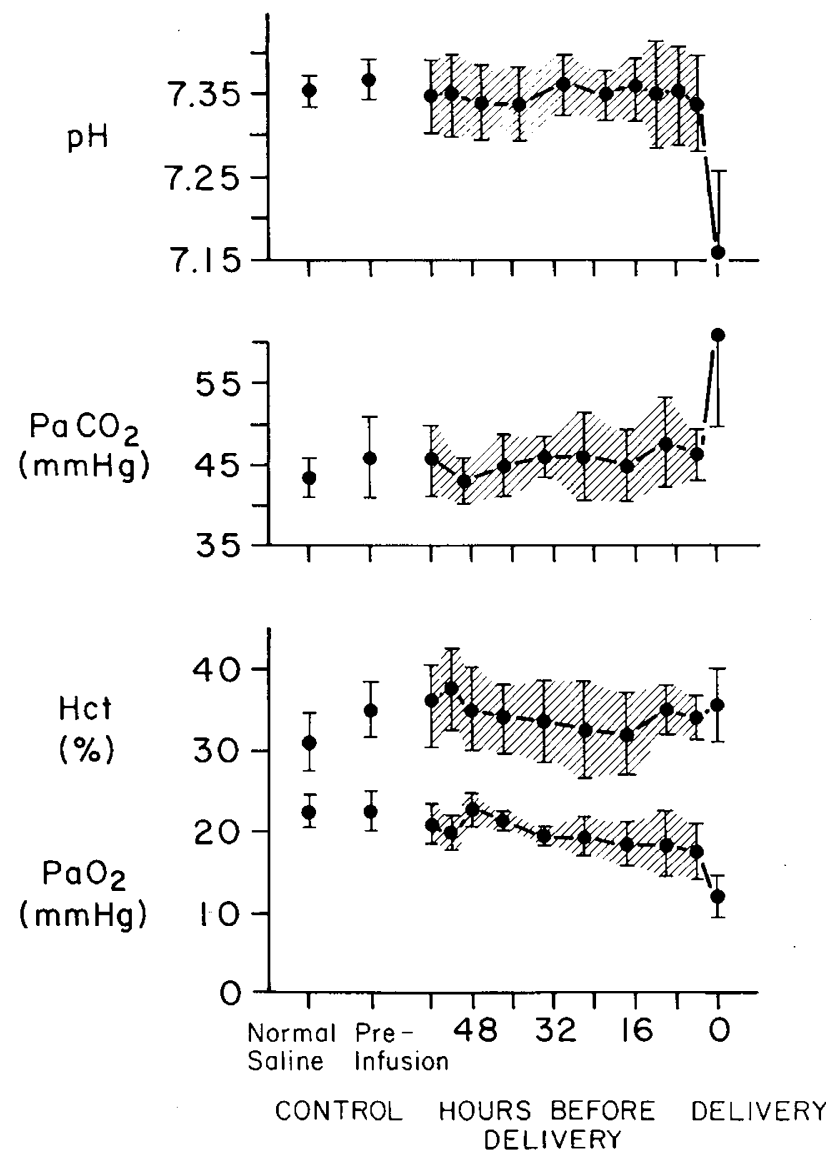

Fig. 2. Fetal arterial $\mathrm{pH}, \mathrm{PO}_{2}, \mathrm{PCO}_{2}$, and hematocrit before and at delivery in seven fetuses infused with $\mathrm{ACTH}$ and in two control fetuses infused with normal saline.
Table 1. The slope and correlation coefficient ( $r$ ) derived from regression analysis of arterial oxygen tension ( $\mathrm{mmHg}$ ) obtained in hours before ACTH-induced delivery in seven individual fetal lambs.

\begin{tabular}{clcr}
\hline Animal & \multicolumn{1}{c}{$\begin{array}{c}\text { Slope }^{1} \\
(\mathrm{~mm} \mathrm{Hg} / \mathrm{hr})\end{array}$} & $r$ & $n^{2}$ \\
\hline 167 & 0.1130 & 0.83 & 11 \\
835 & 0.1194 & 0.68 & 11 \\
116 & 0.0587 & 0.76 & 8 \\
482 & 0.1270 & 0.80 & 16 \\
195 & 0.1010 & 0.80 & 11 \\
396 & 0.1544 & 0.86 & 10 \\
884 & 0.0817 & 0.72 & 14 \\
Mean & $0.1079 \pm 0.0312$ & & \\
\hline
\end{tabular}

${ }^{1} P<0.01$ for the slope in each animal.
${ }^{2} n$, number of determinations per animal.

correlation between maternal and fetal levels of vasopressin during the experiment.

\section{ARTERIAL BLOOD GAS TENSIONS, pH, HEMATOCRIT, OSMOLALITY} AND ELECTROLYTES

The arterial blood gas tensions and $\mathrm{pH}$ during the experiment are presented in Figure 2. During the period of induction before labor, the values for $\mathrm{pH}, \mathrm{PaCO}_{2}$, and hematocrit remained unchanged from control. During labor, there was a progressive increase in variability of $\mathrm{pH}$ and $\mathrm{PCO}_{2}$. At delivery, the mean values were: $\mathrm{pH}, 7.16 \pm .097 ; \mathrm{PCO}_{2}, 61.2 \pm 11.2 \mathrm{~mm} \mathrm{Hg}$; and hematocrit, $34 \pm 13 \%$. This mean packed cell volume was not different from that obtained during the control period.

The mean $\mathrm{PaO}_{2}$ fell progressively during the induction interval. The data from individual fetuses are summarized in Table 1. There was a significant $(P<0.01)$ decrease in the $\mathrm{PaO}_{2}$ in each fetus beginning at least $48 \mathrm{hr}$ before delivery with a mean slope of $0.11 \pm .03 \mathrm{~mm} \mathrm{Hg} / \mathrm{hr}$ and correlation coefficients ranging from 0.68 to 0.86 . Using a weighted mean analysis, this decrease in $\mathrm{PaO}_{2}$ was highly significant $(P<0.001)$.

No significant relationship was established between vasopressin concentrations and $\mathrm{pHa}, \mathrm{PaCO}_{2}$ of $\mathrm{PaO}_{2}$ during the induction phase of the experiment before active labor. The vasopressin values during active and expulsive labor have been plotted logarithmically against $\mathrm{PaO}_{2}$ and $\mathrm{pH}$ (Fig. 3). Linear regression analysis of the data indicated a statistically significant $(P<0.01)$ correlation between the elevation in plasma vasopressin concentration and the fall in both $\mathrm{PO}_{2}$ and $\mathrm{pH}$.

No significant changes in osmolality or electrolytes in fetal plasma were noted during the experiment. In the control period before infusion, mean plasma osmolality was $288.7 \pm 8.0$; during induction before labor, $292.2 \pm 8.9$; during labor, $288.9 \pm 7.6$; and at delivery, $297.8 \pm 12.4 \mathrm{mOsm} / \mathrm{kg}$. Mean plasma electrolyte concentration in $\mathrm{mEq} /$ liter were for sodium, $141.5 \pm 5.6,143.7$ $\pm 4.7,143 \pm 3.7$, and $141 \pm 2.4$; for chloride, $113.0 \pm 5.1,111.6$ $\pm 5.6,109.8 \pm 5.8$, and $112.4 \pm 4.7$; for potassium, $3.5 \pm 0.2,3.8$ \pm 1.0 , and $4.1 \pm 4.7$ during the same intervals as those reported for plasma osmolality.

\section{DISCUSSION}

\section{CONTROL PERIOD}

The resting plasma concentrations of vasopressin in these experiments in both the ewe and her fetus are in accord with our previous studies (23) and those of other investigators (2, 13, 21, 22) using either bioassay or radioimmunoassay techniques for vasopressin determination. These investigations report resting plasma concentrations of the hormone consistently less than 3.5 $\mathrm{mu} / \mathrm{ml}$ or about $10 \mathrm{pg} / \mathrm{ml}$. The vasopressin levels before labor fit nicely within the lower portion of this range with mean fetal levels of $2.0 \pm 1.4 \mathrm{pg} / \mathrm{ml}$ and maternal levels of $2.1 \pm 0.8 \mathrm{pg} / \mathrm{ml}$. The 


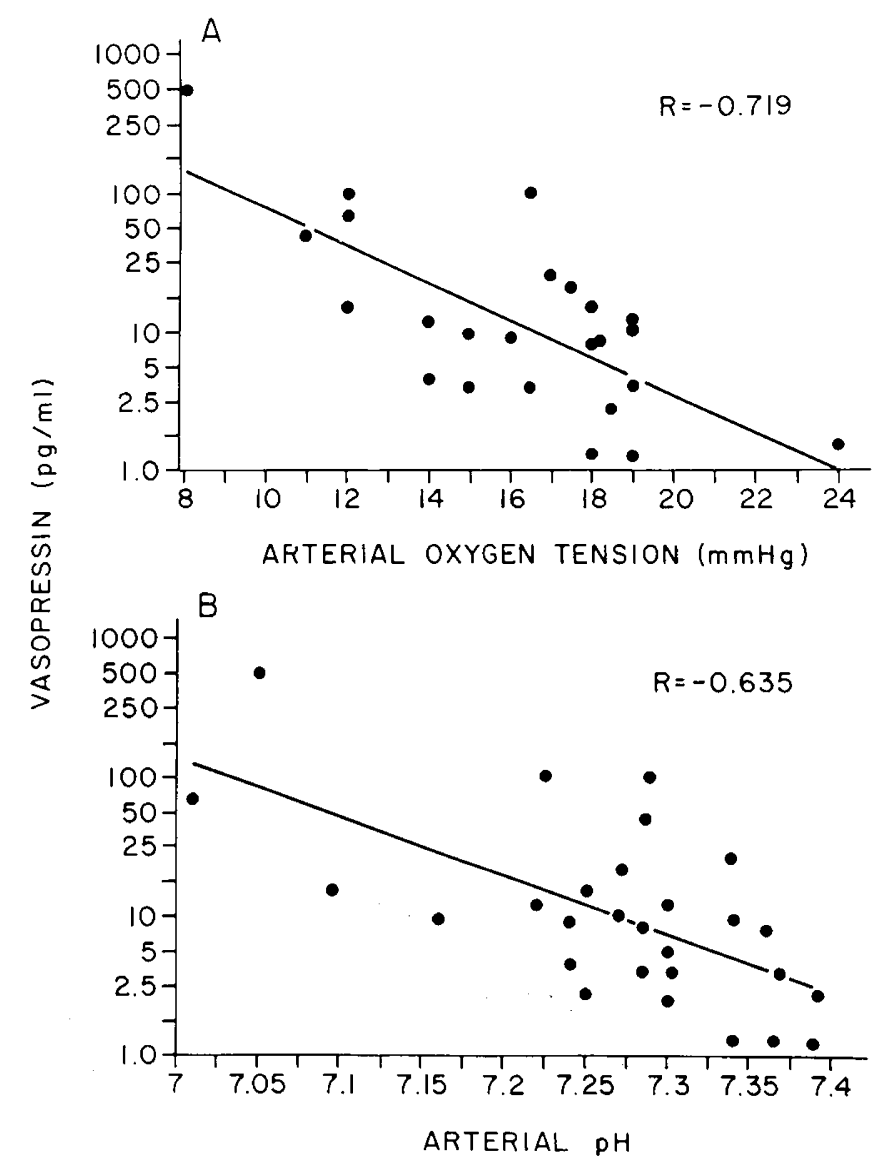

Fig. 3. Relationship between plasma vasopressin concentration plotted logarithmically and arterial $\mathrm{pH}(\mathrm{A})$ or $\mathrm{PO}_{2}$ (B) during active and expulsive phases of labor in seven fetal lambs. The lines were fitted by regression analysis where $\log$ plasma vasopressin concentration $=31.7-4.2$ (arterial $\mathrm{pH})$ and $3.3-0.14\left(\right.$ arterial $\left.\mathrm{PO}_{2}\right),(\mathrm{P}<0.01)$.

mean hormone values observed in this study are lower than have been previously reported. The lower limit of sensitivity of our assay is $0.25 \mathrm{pg} / \mathrm{ml}$ (11) and allows for a precise estimate of resting vasopressin concentration.

In both the present and an earlier report (23), fetal and maternal plasma hormone concentrations were found to vary independently which suggests effective placental impermeability to vasopressin in the sheep. Alexander et al. (1) have reported an almost twofold increase in vasopressin turnover rate in the fetal compartment when compared with the ewe. Although the sheep, unlike the human, lacks significant circulating vasopressin activity (20), it has been suggested that the ovine placenta is a major site for vasopressin clearance from fetal plasma (14) and may be responsible for the more rapid rate of hormone clearance from the fetus.

Before spontaneous labor, we noted modest increases in fetal vasopressin concentration associated with persistent hypoxemic stress (23) while Rurak (21) has observed increases in hormone concentration without deviations from normal values of arterial blood gas tensions, blood pressure, or heart rate. The fetal lamb can release vasopressin in response to osmotic challenge (1), and therefore, fluctuations in vasopressin might be the result of periodic increases in fetal plasma osmolality as described by Mellor et al. (18). In the present study, there were variations in plasma osmolality among individual animals, but no correlation between plasma osmolality and vasopressin concentration was observed.

\section{LABOR INDUCTION AND BIRTH CHARACTERISTICS}

The signs of impending premature labor induced with infusion of ACTH to the fetus were remarkably similar to those reported before spontaneous parturition (18). These included distention of the udder and behavioral changes. It is interesting to note that these clinical signs were apparent before the onset of uterine contractions. Data related to duration of the various phases of $\mathrm{ACTH}$ induction as well as the observation that twin pregnancies required more prolonged infusion of $\mathrm{ACTH}$ are comparable to the observations of Liggins et al. (17). In both instances when one of a pair of immature twin fetuses was infused with ACTH, the treated fetus delivered first. This sequence is said to be invariable and has been taken as evidence to support the notion of local intrauterine control of the timing of labor (16).

\section{VASOPRESSIN CONCENTRATIONS}

Fetal vasopressin concentrations rose significantly during the active and expulsive phases of ACTH-induced labor (Fig. 1) in a similar fashion to that we have previously described during spontaneous labor. These data further reinforce the postulate that fetal vasopressin secretion increases in response to labor and not before labor. They do not support the concept that fetal vasopressin is integrally related to the onset of parturition, as others have suggested (5).

Vasopressin hypersecretion into the fetal lamb circulation is not just a momentary phenomenon occurring at delivery, but also proceeds during active labor. The significant correlations between elevated vasopressin concentrations in lamb plasma at delivery with the hormone concentrations obtained in the latter stages of labor may be important in interpreting data obtained from human umbilical cord blood. High concentrations of the hormone are found in human fetal plasma at vaginal delivery $(6,10,19)$. These observations of vasopressin hypersecretion at the moment of birth may similarly imply a more prolonged exposure of the human fetus to vasopressin at concentrations which may have extensive effects on the fetal cardiovascular system.

One of the factors responsible for vasopressin release in the latter stage of delivery may be mechanical compression of the fetus during uterine contractions and passage through the cervical canal. Hadeed et al. (10) have attributed the hypersecretion of vasopressin during normal human labor to cerebral compression. We have observed a parallel phenomenon in the rat where body compression for $60 \mathrm{sec}$ before decapitation results in an 100-fold increase in vasopressin levels (12). It is speculated that compression causes impaired oxygenation and/or hemodynamic alterations which trigger vasopressin release.

\section{ARTERIAL BLOOD GAS TENSION, pH, AND HEMATOCRIT}

A number of stressful conditions including hypoxia (4), umbilical cord compression (9), hemorrhage (3), and infusion of hypertonic saline (1) have been associated with a concurrent release of vasopressin. In the present study, a significant inverse correlation between fetal plasma vasopressin concentration and arterial oxygen tension and $\mathrm{pH}$ was apparent during the latter stages of labor. Reduction in fetal oxygen supply and subsequent acidemia thus appears to be one of the potential stimuli to vasopressin release during labor. Furthermore, there is evidence from several sources $(13,21)$ that vasopressin may play an important role in the redistribution of fetal cardiac output in response to hypoxemia.

Vasopressin concentrations did not increase in the two fetuses during the control studies where blood samples were obtained at the same frequency as animals with induced labor. These data would imply that the cumulative effect of this degree of hemorrhage was insignificant.

The values for $\mathrm{pHa}, \mathrm{PaCO}_{2}$, hematocrit (Fig. 2), osmolality, and electrolytes in fetal blood obtained during ACTH induced labor do not differ from those obtained by others $(8,18)$ during spontaneous parturition. An unexpected exception to this finding was the highly significant sequential decrement in $\mathrm{PaO}_{2}$ in each ACTHinfused fetus (Table 1). This decrease in fetal $\mathrm{PaO}_{2}$ appeared to begin before the onset of labor. It is doubtful that this change in oxygen tension reflected a gradual deterioration of the fetuses because control animals subjected to the same protocol with saline 
infusion remained normoxemic. It is equally doubtful that ACTH infusion had a significant and progressive effect on uterine blood flow. Studies by Towell and Liggins (24), although limited in the number of observations, depict changes in uterine blood flow during ACTH-induced labor that are similar to those observed after the spontaneous labor at term. An alternative explanation for the decrement in $\mathrm{PaO}_{2}$ comes from examination of the maternal and fetal tissues within the placenta reported by Liggins (16). He suggests that degenerative changes in the syncytium with progressive disruption of the fetal maternal interface occur before both spontaneous term and ACTH-induced preterm parturition. These morphologic changes might be sufficient to lead to progressive fetal hypoxemia.

\section{CONCLUSION}

There is a significant hypersecretion of vasopressin in the fetus but not the ewe during the latter stages of parturition. Elevated plasma concentrations of the hormone persist in the newborn plasma to at least one-half $\mathrm{hr}$ of age. Fetal hormone levels in umbilical cord blood are highly predictive of levels before delivery. The strong inverse correlation of fetal vasopressin concentration and $\mathrm{pHa}$ and $\mathrm{PaO}_{2}$ may imply a causal relation between hypoxia and vasopressin secretion during labor. No similar correlations were observed with changes in plasma osmolality or electrolytes. These and other characteristics of parturition prematurely induced with ACTH mimic those of spontaneous labor although we observed, unexpectedly, a significant progressive decrease in fetal arterial oxygen tension during the induction process. It is doubtful that this gradual hypoxemia was a significant stimulus to vasopressin secretion, but may be the result of progressive disruption of the fetal-maternal interface as parturition progresses in both prematurely induced and spontaneous labor.

\section{REFERENCES AND NOTES}

1. Alexander, D. P., Bashore, R. A., Britton, H. G., and Forsling, M. L.: Antidiuretic hormone and oxytocin release and antidiuretic hormone turnover in the fetus, lamb and ewe. Biol. Neonate, 30: 80 (1976).

2. Alexander, D. P., Bashore, R. A., Britton, H. G., and Forsling, M. L.: Maternal and fetal arginine vasopressin in the chronically catheterized sheep. Biol. Neonate, 25: 242 (1974)

3. Alexander, D. P., Britton, H. G., Forsling, M. L., Nixon, D. A., and Ratcliff, J. G.: Pituitary and plasma concentrations of adrenocorticotrophin, growth hormone, vasopressin and oxytocin in fetal and maternal sheep during the latter half of gestation and response to hemorrhage. Biol. Neonate, 24: 206 (1974).

4. Alexander, D. P., Forsling, M. L., Martin, M. J., Nixon, D. A., Ratcliff, J. G., Redstone, D., and Tunbridge, D.: The effect of maternal hypoxia on fetal pituitary hormone release in sheep. Biol. Neonate, 21: 219 (1972).

5. Challis, J. R. G., and Thorburn, G. D.: The fetal pituitary. In: R. W. Beard, P. W. Natanielsz: Fetal Physiology and Medicine. pp. 233-253 (W. B. Saunders Co., Philadelphia, 1976).

6. Chard, T., Boyd, N. R. H., Edwards, C. R. W., and Hudson, C. N.: The release of oxytocin and vasopressin by the human fetus during labor. Nature (Lond.), 234: 352 (1971).

7. Cloete, J. H. L.: Prenatal growth in the Merino sheep. Onderstepoort. J. Vet. Sci. Anim. Ind., 13: 417 (1939).

8. Comiline, R. S., and Silver, M.: The composition of foetal and maternal blood during parturition in the ewe. J. Physiol. (Lond.), 222: 233 (1972).

9. Daniel, S. S., Husain, M. K., Milliez, J., Stark, R. I., Yeh, M. N., and James, L. S.: Renal response of the fetal lamb to complete occlusion of the umbilical cord. Am. J. Obstet. Gynecol., 131: 514 (1978).

10. Hadeed, A. J., Leake, R. D., and Weitzman, R. E.: Possible mechanisms of high blood levels of vasopressin during perinatal period. J. Pediatr. 94: 805-808, (1979).

11. Husain, M. K., Fernando, N., Shapiro, M., Kagan, A., and Glick, S. M.: Radioimmunoassay of argining vasopressin in human plasma. J. Clin. Endocrinol. Metab., 37: 616 (1973).

12. Husain, M. K., Manger, W. M., Rock, T. W., Weiss, R. J., and Frantz, A. G.: Vasopressin release due to manual restraint in the rat: role of body compression and comparison with other stressful stimuli. Endocrinology, 104: 641 (1979).

13. Iwamoto, H. S., Rudolph, A. M., Keil, L. C., and Heymann, M. A.: Hemodynamic responses of the sheep fetus to vasopressin infusion. Circ. Res, 44:430 (1979).

14. Jones, G. T., and Rurak, D.: The distribution and clearances of hormones and metabolities in the circulation of the foetal sheep. Q. J. Exp. Physiol. Cogn. Med. Sci., 61: 287 (1976)

15. Liggins, G. C.: Premature parturition after infusion of corticotropin or cortisol into fetal lambs. J. Endocrinol., 42: 323 (1968).

16. Liggins, G. C.: Initiation of parturition. Br. Med. Bull., 35: 145 (1979).

17. Liggins, G. C., Fairclough, R. L., Grieves, S. A., Kendall, J. Z., and Knox, B. S.: The mechanism of initiation of parturition in the ewe. Rec. Prog. Horm. Res., 29: 111 (1973).

18. Mellor, D. J., Smith, B. S. W., and Matheson, 1. C.: Preparturient changes in all antoic fluid and fetal plasma from chronically catheterized ewes. Res. Vet. Sci., 18: 328 (1975)

19. Polin, R. A., Husain, M. K., James, L. S. and Frantz, A. G.: High vasopressin concentrations in human umbilical cord blood. J. Perinat. Med., 5: 114 (1977).

20. Rosenbloom, A. A., Sack, J., and Fisher, D. A.: The circulating vasopressinase of pregnancy: species comparison with radioimmunoassay. Am. J. Obstet. Gynecol., 121: 316 (1975).

21. Rurak, D. W.: Plasma vasopressin levels during hypoxemia and cardiovascular effects of exogenous vasopressin in foetal and adult sheep. J. Physiol. (Lond.), 277: 341 (1978).

22. Skowsky, W. R., Bashore, R. A., Smith, F. G., Jr., and Fisher, D. A.: Vasopressin metabolism in the fetus and newborn. In: R. S. Comiline, K. W. Cross, G. S. Dawes, P. W. Natanielsz: Fetal and Neonatal Homeostasis. Proc. Sir Joseph Barcroft Centenary Symp. pp. 439-477 (Cambridge University Press, Cambridge, England, 1973).

23. Stark, R. I., Daniel, S. S., Husain, K. M.. James, L. S., and Vande Wiele, R. L.: Arginine vasopressin during gestation and parturition in sheep fetus. Biol. Neonate, 35: 235 (1979)

24. Towell, M. E., and Liggins, G. C.: The effect of labor on uterine blood flow in the pregnant ewe. Q. J. Exp. Physiol. Cogn. Med. Sci., 61: 23 (1976).

25. Weitzman, R. E., and Fisher, D. A.: Log linear relationship between plasma arginine vasopressin and plasma osmolality. Am. J. Physiol., 233: 37 (1977).

26. The present address of Dr. J. Milliez is: Clinique Universitaire Baudelocque, 123 Boulevard Port-Royal, 75014 Paris, France.

27. The authors wish to thank Janice Williams for her technical help in conducting these experiments.

28. Requests for reprints should be addressed to: Dr. Raymond I. Stark, Columbia College of Physicians and Surgeons, Department of Pediatrics, 630 W. 168th Street, New York, NY 10032 (USA).

29. This research was supported in part by a Grant from the National Foundation 1-484 and NIH HD-13063.

30. Received for publication October $7,1980$.

31. Accepted for publication January 22, 1981. 